\title{
Accuracy of blood pressure-to-height ratio for screening elevated blood pressure in Egyptian adolescents aged 11-15 years
}

\section{Mirella Youssef Tawfik}

Department of Community Medicine, College of Medicine, Suez Canal University, Ismailia, Egypt

Received :January 2017Accepted : March 2017

\section{Abstract}

Objective: This study aims to validate measures of blood pressure-to-height ratios (BPHR) in screening for elevated blood pressure (EBP) in a sample of the Egyptian adolescence aged 1115 years.Methods: A cross sectional study was conducted on a sample of 1707 students aged 11-15 years. Elevated blood pressure was defined according to the international gold standard definition. Systolic and diastolic BPHR (SBPHR and DBPHR) were calculated for boys and girls, and their ability to identify EBP has been determined by the area under the curve of the receiver operator characteristic curves. Sex-specific optimal cut-off points were determined along the curve, and their sensitivity, specificity, positive and negative predictive values (PPVs, and NPVs), and positive and negative likelihood ratios (LR+, and LR-) were estimated. Results: The accuracy of SBPHR and DBPHR in diagnosing EBP in both sexes ranged from 0.906 to 0.981 . For diagnosing systolic and diastolic pre-hypertension (preHTN), the optimal cut-off points were: $0.69,0.44$ in boys, and $0.71,0.46$ in girls respectively. For diagnosing systolic and diastolic hypertension (HTN), the corresponding values were $0.75,0.49$, and $0.75,0.50$ respectively. These determined cut-off points revealed high sensitivity (0.88-1.00), moderate to high specificity (0.77-0.95), high NPVs (0.99-1.00), low PPVs (0.15-0.38), and variable likelihood ratio values (LR+: 3.8-20.0, and LR-: 0.0.36.0).Conclusion: Blood pressure-to-height ratios are considered of high accuracy in identifying pre-HTN and HTN in the Egyptian adolescents aged 11-15 years. Further research is needed for examining the performance of the BPHR in other age groups, in high risk adolescents, and for examining the performance of modified ratios.

Keywords: Adolescents, blood pressure-to-height ratios, elevated blood pressure, prehypertension, hypertension

Correspondence to:Mirella Youssef Tawfik E-mail: $\underline{\text { mirellatawfik@hotmail.com }}$

\section{Introduction}

In Egypt, there is an apparent developing epidemic of premature cardiovascular mortality, and elevated blood pressure (EBP) was considered the main clinical risk factor responsible for this epidemic ${ }^{1}$. There is a growing evidence that EBP appears earlier in life, in some cases in childhood and adolescence ${ }^{2}$. Worldwide, many studies have documented an increased incidence of EBP in childhood, and confirmed the predisposition for both a greater risk of hypertension (HTN) and cardiovascular morbidity later in life ${ }^{3-6}$. About $10 \%$ of the Egyptian children and adolescents have $\mathrm{EBP}^{7}$, and this rate is expected to increase with the current increased rate of childhood and adolescence overweight and obesity that 
exceeded $45 \%$ in our country ${ }^{8}$. Therefore, there was an urgent need for the diagnosis and treatment of pre-hypertension (preHTN) and HTN early in life, as this may result in lifelong reduction in the risk of their occurrence as well as the occurrence of associated conditions ${ }^{4}$.

Based on a gold standard guidelines developed for the definition of normal and EBP in children and adolescents, accurate diagnosis of EBP requires adjusting the values for age, gender, and height ${ }^{9}$. This adjustment requires measuring the child's height, determining the child's height's percentile based on national or international height tables, measuring and recording the child's blood pressure (BP), and finally checking if his BP falls within or above the corresponding BP percentiles in the BP tables. This cumbersome process makes the interpretation of the BP level time consuming and too complex to be applied in everyday paediatric clinical practice $^{10,11}$. Providing simple approaches for interpreting BP levels in childhood and adolescence would encourage health care providers to include blood pressure $\mathrm{BP}$ measurement as an integrated part of physical examination for healthy children and adolescents.

$\mathrm{Lu}$ and his colleagues ${ }^{12}$ have took the advantage of the positive correlation between height and BP in childhood and young adulthood ${ }^{(13)}$, and have developed an index ratio using these two components. They hypothesized that as height is an important determinant of blood pressure in adolescents, a ratio of blood pressure-toheight (BPHR) can be used for screening of paediatric and adolescence EBP. They indicated that the new tool was accurate for the diagnosis of EBP among Chinese adolescents, and recommended examining the accuracy of this tool in various populations; as the variability in anthropometric indices among different ethnic groups may imply that the findings may not be applicable in all populations. Information regarding the accuracy of BPHR to define EBP in the Egyptian adolescence population is scarce. This study aims to calculate the validity measures of BPHR in screening for EBP in a sample of the Egyptian adolescence aged 11-15 years.

\section{Methods}

Study design, setting and time A cross sectional study was conducted in the urban governmental primary and preparatory schools of Ismailia-Egypt, in two months period (October and November 2016). Schools and classes $\left(6^{\text {th }}\right.$ primary grade, and $1^{\text {st }}-3^{\text {rd }}$ preparatory grades) were selected using two-stage random sample technique. In the first stage four schools were randomly selected, and in the second stage, four subclasses ( 2 subclasses/ gender) were randomly selected from each grade subclasses in the four schools. Finally, all eligible students of the selected classes were included in the study.

Study population: Because the study aim was to screen for EBP among healthy adolescents, all recruited participants were required to be healthy.Parents of all eligible students were asked to report if their children have history of chronic diseases, and students' medical records were checked regarding chronic endocrine, renal, cardiovascular or congenital disorders, those with positive data have been considered non-eligible for recruitment.

Administrative preparation and ethical Approval: Official permissions have been obtained from the Ministry of Education and from principals of sampled schools. Parents of recruited students were informed about the aim of the study and were asked to approve for a written informed consent. Students who showed 
their parents' written consent as well as had orally accepted to participate were eligibly included in the study. All procedures performed were in accordance with the ethical standards of the Research Ethics Committee of Suez Canal University in Ismailia-Egypt (approval number: 2898).

Sample size: Sample size of the current study was estimated on the basis of the recently provided tables of the total required sample sizes for estimating sensitivity and specificity with respect to marginal error, sensitivity and specificity and the prevalence of disease in target population $^{(14)}$. Using sensitivity and specificity values of the BPHR in adolescence aged 13-18 years (95\% and $85 \%$ respectively) ${ }^{(15)}$, and maximum marginal error of 0.05 , a minimum sample of 1666 male and female (1460 and 206 participants for determining sensitivity and specificity respectively) participants were needed for examining the test screening ability. The selected subclasses of all grades in the four selected schools included a total of 920 and 932 eligible boys and girls respectively. A total number of 853 boys (response rate $=92.7 \%$ ) and 854 girls (response rate $=91.6 \%$ ) accepted to participate.

Data collection tools: Height and weight were measured using the balance beam scale with the height rod. Blood pressure was measured using a stethoscope and a standardized auscultation mercury sphygmomanometer with manually inflated cuff of suitable size. The age of students was obtained from their birth certificates, and age to the nearest month at the time of measurement was recorded for each student.

Study procedure and techniques: Assessment of height, weight, body mass index (BMI) and blood pressure: These were measured and recorded in school clinics by the researcher with the assistance of school health visitors. Students were asked to stand in light clothing without shoes, with parallel feet and looking straight. Height and weight were measured to the nearest $0.1 \mathrm{~cm}$ and $0.1 \mathrm{~kg}$ respectively. MI was calculated as weight divided by squared height $\left(\mathrm{kg} / \mathrm{m}^{2}\right)$. Sex- and age-specific percentiles of height were derived from the WHO height-forage 5-19 years percentiles/sex cut off points ${ }^{16}$. Because of the non-availability of the $10^{\text {th }}$ and $90^{\text {th }}$ percentiles in these tables, the height's z-score and its related percentile was estimated (based on the sex and age specific mean height and standard deviation available in these tables) for children whom their heights lay in the corresponding ranges between $5^{\text {th }}-15^{\text {th }}$ and $85^{\text {th }}-95^{\text {th }}$ percentiles. Child's height percentile was defined to be in the $10^{\text {th }}$ percentile if it was $\geq 10^{\text {th }}$ and $<25^{\text {th }}$, and defined to be in the $90^{\text {th }}$ percentile if it was $\geq 90^{\text {th }}$ and $<95^{\text {th }}$ percentile. Blood pressure was measured and interpreted based on the recommendation of the National High Blood Pressure Education Program Working Group in Children and Adolescents(NHBPEP) ${ }^{9}$. Two measurements (at 2-min intervals) were recorded, and the average SBP and DBP values were compared with those provided in the NHBPEP tables for boys and girls according to the student's age and height percentile. Pre-HTN was defined as either average systolic blood pressure (SBP)/diastolic blood pressure (DBP) greater than or equal to the referent sex-, age-, and height-specific $90^{\text {th }}$ percentile or $\mathrm{SBP} / \mathrm{DBP} \geq 120 / 80 \mathrm{~mm} \mathrm{Hg}$, and hypertension was defined as average SBP/DBP $\geq 95$ th sex-, age-, and heightspecific percentile ${ }^{(9)}$. Students whom their blood pressure averages values were $\geq 90^{\text {th }}$ percentile in the first screening underwent two other evaluations for their blood

Vol. 36 No. 1 January 2018 
pressure one week apart. Elevated blood pressure was determined when the average of their SBP and/or DBP is $\geq 90^{\text {th }}$ percentile in the three occasions ${ }^{(9)}$. Systolic BPHR (SBPHR) was calculated as SBP/height $(\mathrm{mm} \mathrm{Hg} / \mathrm{cm})$, and diastolic BPHR (DBPHR) as DBP/height $(\mathrm{mm} \mathrm{Hg} / \mathrm{cm})^{12}$. The BPHR had high accuracy values that ranges from approximately $80 \%{ }^{10}$ to $<85 \%{ }^{12}$.

\section{Statistical analysis}

Data entry and analysis was performed using SPSS version 19. Frequencies and percentages were used for presenting categorical variables, and means \pm SD were used for presenting continuous variables. Chi square, Fisher's exact test, and Student's t tests were used for testing the significance of differences in study variables between boys and girls. Pearson correlation was used to test for correlation between BPHR and subjects clinical characteristics. The receiver operator characteristic (ROC) curves were generated to test the ability of the SBPHR and DBPHR to discriminate between normal and pre-HTN, and between normal and pre-HTN (as one category) and HTN in boys and girls separately. The ROC curves discriminating ability was measured by the area under the curve (AUC). The screening tool was considered as an excellent accurate test if it has an AUC value of $0.9-1$, good test if AUC value is $0.8-<0.9$, worthless test if AUC value is $0.7-<0.8$, and not a good test if AUC value is $0.6-<0.7^{17}$. Sensitivity and specificity of both SBPHR and DBPHR were calculated at all range of possible cut-off points in the ROC curves to find the optimal cut-off points. The optimal cut-off point is the point where the sensitivity and specificity values yielding maximum sums from the ROC curve. Optimal cut-off points were used for classifying the studied subjects into positives and negatives, and sensitivity, specificity, positive and negative predictive values (PPVs, and NPVs respectively) and positive and negative likelihood ratios (LR+, and LR-) were calculated.

\section{Results}

The mean heights of the boys in the younger age (11 and 12 years) were lower than that of the girls without showing statistical significance in difference between both sexes $(p>0.05)$. At the age of 13 years the mean heights in both sexes were nearly equal. In the older age (14 and 15 years) the boys were significantly taller than the girls $(p<0.001)$. Boys and girls have nearly equal mean weights and BMI (at all given ages for weight, and at the age of 11-13 years for BMI) that didn't show statistical significance in difference $(p>$ 0.05). The girls had significantly higher BMI compared to the boys at the older age $(14,15$ years $)(\mathrm{p}<0.001)$ (Table 1$)$.

The mean SBP in boys was higher than that of girls in all ages, but differences didn't show statistical significance at any given age $(p>0.05)$. The mean DBP in boys was higher than that of girls in the younger age (11-13 years), and showed statistical significance at the age of 11 and 13 years $(p<0.05)$. At the older age, the girls showed higher mean DBP values compared with the boys with statistical significance in difference at the age of 14 years $(p<0.001)$. The mean DBPHR and SBPHR were higher in girls than in boys in the older age (13-15 years) with statistical significance in difference at the age of 15 years for SBPHR $(\mathrm{p}<0.05)$, and at the age of 14 and 15 years for DBPHR ( $p<0.001$ and 0.01 respectively) (Table 1 ).

The overall prevalence rates of elevated systolic and diastolic blood pressure were $10.6 \%$ and $8 \%$ respectively. The prevalence rates of systolic and diastolic pre-HTN were higher in girls than in boys 
(6.9\% and $6.2 \%$ for systolic pre-HTN; and $6.4 \%$ and $5.8 \%$ for diastolic pre-HTN respectively). The prevalence of systolic and diastolic HTN was higher in boys than in girls $(4.5 \%$ and $3.6 \%$ for systolic HTN; and $2.5 \%$ and $1.3 \%$ for diastolic HTN respectively). Differences in the prevalence rates of different levels of SBP and DBP between both sexes didn't show statistical significance $(\mathrm{p}>0.05)$ (Table 2$)$.

The correlation analysis showed that both SBP and DBP were positively correlated with height $(\mathrm{p}<0.001)$, and that both SBPHR and DBPHR were negatively and positively correlated significantly $(\mathrm{p}<0.001)$ with height and BMI respectively. Both SBPHR and DBPHR were positively and significantly correlated with SBP and DBP respectively $(\mathrm{p}<0.001)$, with very strong correlation coefficients (>0.8). Both SBP and DBP were positively and significantly correlated $(\mathrm{p}<0.001)$ with age and anthropometric variables (Table 3).

The AUC values for the accuracy of both SBPHR and DBPHR in diagnosing both pre-HTN and HTN in both sexes ranged from 0.906 to 0.981 , and values were higher in diagnosing HTN than pre-HTN in both boys and girls (Fig. 1). The optimal cut-off points for diagnosing systolic preHTN were 0.69 in boys and 0.71 in girls; while values for diastolic pre-HTN were 0.44 for boys and 0.46 for girls. The optimal cut-off points for diagnosing systolic HTN were 0.75 in both boys and girls; while values for diastolic HTN were 0.49 for boys and 0.50 for girls. Sensitivities (ranging from 94\% to $100 \%$ ) and specificities (ranging from $92 \%$ to 95\%) for both systolic and diastolic HTN were higher than that of systolic and diastolic pre-HTN (ranging from $88 \%$ to $97 \%$ for sensitivities, and from $77 \%$ to $87 \%$ for specificities respectively). Specificity was lower than sensitivity The Egyptian Journal of Community Medicine across all categories of HTN and pre-HTN. Optimal cut-off points showed a high NPVs ranging from .98-1 in all categories although the PPVs were low (ranging from 0.15 to 0.38 ). The LR+ and LR- for diagnosing pre-HTN ranged from 3.8-7.1, and from 0.03-0.36 respectively, and for diagnosing HTN, the corresponding ratios ranged from 11.7-20, and from 0-.06 respectively (Table 4).

\section{Discussion}

The increasing prevalence of adolescents' high blood pressure in our country ${ }^{18}$ supports the recent global need for the routine blood pressure measurement and screening in this period of rapid growing. This may help to identify adolescents who are at increased risk of developing hypertension and cardiovascular morbidity later in life, and would enable for early and proper management ${ }^{4}$.The complicated diagnostic criteria of the gold standard definition reported by the NHBPEP with age, gender and height specific standards for SBP and $\mathrm{DBP}^{(12)}$ is a probably reason that explains why in Egypt, and in many other countries; screening for EBP is generally less regularly performed in clinical practice ${ }^{11,19}$ and why hypertension is frequently under-diagnosed in children whose BP is measured ${ }^{20}$. Providing simple tools would allow for easier interpretation of BP values, and would help to determine those who need further evaluation for definitive diagnosis. The BPHR index is a tool that factors in "age, gender and height", while removing the noted encumbrances of the gold standard tool ${ }^{12}$. In our resource-poor country with low health care providers/patients ratio, this tool would be ideal for adolescents' BP screening. To the researcher knowledge, the current study is the first in Egypt that examines the performance of the BPHR for identifying EBP in adolescents, and

Vol. 36 No. 1 January 2018 
determines the optimal cutoff points for detecting pre-HTN and HTN in this population.

Based on the gold standard definition ${ }^{9}$, the prevalence rates of pre-hypertension and hypertension in this study were similar to those of a previous study done on the Egyptian adolescents aged 11-19 years ${ }^{7}$. Similar studies conducted in other countries showed lower $(7 \%, 7.2 \%)^{21,22}$,or greater rates $(18.2 \%, 22 \%)^{23,24}$ than those estimated in our country. This could be due to the ethnic differences in BP patterns among the studied groups of adolescents, and/or the inappropriateness of using one single diagnostic tool across different racial populations ${ }^{25,26}$.

The significantly higher BPHR values in girls of older age compared to boys of the same age were in agreement with results of previous studies that used the same diagnostic criteria for identifying EBP among the same age group of adolescents $^{12,24,27,28}$. This could be due to the higher height values that nullified the effect of the higher SBP in boys compared to girls; with a resultant relatively higher girls' SBPHR quotient; and the combined effect of the higher DBP and the lower height values in girls with resultant higher girls' DBPHR quotient.

The absence of significant correlation between BPHR and age in the current study was in agreement with results of a previous study ${ }^{27}$. Correlation analysis between these studied variables showed conflicting results in other studies, with significantly negative correlations ${ }^{29}$ in one study, non-significantly negative correlation in another study ${ }^{12}$, and significantly positive correlations but for girls only in a third study ${ }^{30}$. Performing the analysis on younger age group in the first study and performing gender-stratified correlation analysis in the second and third studies didn't allow for appropriate comparison. The absence of significance in the correlation between BPHR and age combined with the significantly negative correlation between BPHR and height indicated that justifying BP to height in the BPHR index has compensated for the effect of age on BP (that was indicated by the significant positive correlation between age and BP). This implies that if BPHR cut-off points have been determined (for both sexes) for identifying normotensive and hypertensive adolescents, age will not further be needed for establishing the diagnosis of EBP.

The correlation results between BPHR on one hand and height as well as BP on the other hand were consistent with results of a previous study ${ }^{27}$. The significantly strong positive correlation between BPHR and BP indicates the valid performance of the new tool. The significantly negative correlation between BPHR and height clarifies that shorter adolescents had relatively higher BPHR values, and that taller adolescents had relatively smaller values. This performance is better than that of the SBP and DBP in identifying those with high blood pressure, as it ensures that tall adolescents who have normal weights are not misclassified as hypertensives or short and heavy adolescents are not misclassified as normotensives, as was the case when only a single value for blood pressure was used for each age $\mathrm{e}^{31}$.

In this study, the areas under the ROC curves of SBPHR and DBPHR were consistent with robust diagnostic performance (ranging from 0.906 to 0.981), and indicated powerful discriminative abilities to identify those with normal and those with elevated SBP and DBP in adolescents' of both sexes. These results were consistent with those of previous studies conducted in various countries $^{12,27,32}$. However a relatively higher discriminating power has been 
documented in a previous study (ranging from 0.95 to 0.99 ) where authors have analysed all children with BP $>90^{\text {th }}$ percentile for age and sex as one group, and didn't differentiate between pre-HTN and $\mathrm{HTN}^{33}$. The higher accuracy of the ROC curves in discriminating HTN compared to pre-HTN was similar to findings in similar studies, where AUC values increased with the degree of HTN in children and adolescents ${ }^{24,30,34}$.

When optimal SBPHR and DBPHR cut-off point values have been applied for identifying systolic and diastolic pre-HTN and systolic and diastolic HTN in both sexes, the sensitivities and specificities had values that were $\geq 85 \%$ (except for the specificity of the SBPHR cut-off point value for detecting pre-HTN in boys). Sensitivity and specificity values as well as their optimal cut-off points have been shown to differ among previous studies ${ }^{2,27-}$ 30,32 . These findings could be due to the difference in age range applied in these studies as well as the variation in race/genetics among studied populations $^{25,26}$.Establishing countryspecific cut-off point values will respect the existing racial and genetic differences among various populations, and will help in the identification of adolescents with elevated BP based on native references. In the current study, the higher sensitivities and specificities of the BPHR in identifying HTN in comparison with preHTN were in agreement with previous studies and confirmed the better ability of the test for identifying hypertensives versus pre-hypertensives. Also, the higher sensitivity than specificity across all categories of HTN and pre-HTN in both sexes supported previous findings $12,27,30,33,34$. This matches the purpose of this screening index, as it is desirable to have a low rate of false negative subjects who may miss diagnosis than to have a low rate of false positives who can be further excluded.

The very high NPVs and the low PPVs of selected cut-off points in the current study were also consistent with results of previous studies ${ }^{28-29}$. Predictive values reflect the diagnostic power of the test, and are dependent on sensitivity, specificity and disease prevalence. The low PPVs in the current study could be due to the low prevalence of disease in the studied population. However, predictive values in the current study ensure that there is no need for performing further investigations to those who were identified as having normal BP by the BPHR index, which would enable health care providers to better rationalize their time and efforts for verifying the diagnosis and providing the needed management to those who were identified as having EBP. This is important in our resource-limited country, where few numbers of clinicians have to attend for large number of children and adolescents. The likelihood ratios reflect the value of performing a diagnostic test and are independent of the disease prevalence. In the current study, the likelihood ratios of the BPHR among adolescents with HTN provide a strong evidence to rule in/ rule out the presence of the disease $(\mathrm{LR}+>10$, and $\mathrm{LR}-<.01)^{35}$ compared to those with pre-HTN. This was consistent with results of a previous study ${ }^{27}$. This evidence is relatively lower among adolescents with pre-HTN, albeit the corresponding LR+ and LR- still show good probabilities for presence or absence of the disease $(>1$ and $<1$ respectively) $)^{35}$.

\section{Limitations}

This study has a few limitations. First, the low prevalence of the disease in the examined population with the corresponding low test PPVs. However, the probability of BPHR to rule in the presence of the disease among those who 
were positive; independently on disease prevalence was high (as shown by the high LR+ values), especially among those with HTN, which proved the importance for applying the test among those who were classified as positive by the test. Second, the dependence on the WHO international height percentile references (due to the non-availability of a national Egyptian height percentile reference for this age group), with a probability of a gold standard misclassification error (in case if a valid difference exists between both national and international continuum). However, the strong positive correlations between the BPHR index and BP helped in proving the stability of the index accuracy and nullified the possible effect of this error.

\section{Conclusions}

In conclusion, BPHR is a simple and accurate index for identifying EBP in the Egyptian adolescents aged 11-15 years. It has reduced the number of needed cutoff points from two hundred eighty (the product of multiplying two cutoff points of gender, by two cutoff points of pre-HTN and HTN, by two cutoff points of diastole and systole, by five 5 cutoff points of age, by seven cutoff points of different BP percentiles for each corresponding age) to eight cutoff points ( 2 cutoff points, one for each gender, 2 cutoff points one for preHTN and one for HTN, 2 cutoff points one for diastole and one for systole) with a high discriminating power. Further studies are needed for identifying cutoff point values for EBP in other age group categories in Egypt, for investigating the performance of the BPHR index in high risk adolescents population (smokers, with high BMI and/or a positive family history of EBP), and for examining the modifiable effect of other index ratios that consider different anthropometric measures as weight, BMI, and waist circumference on increasing the screening validity.

\section{References}

1) World Health organizationNoncommunicable diseases (NCD) Country Profiles, (2014). Accessed on August 2016 at http://www.who.int/nmh/countries/eg y_en.pdf.

2) Dyson PA, Anthony D, Fenton B, Matthews DR, Stevens DE (2014). Community Interventions for Health

Collaboration.High rates of child hype rtension associated with obesity: a community survey in China, India a nd Mexico. Paediatrics and International Child Health; 34:43-49.

3) Falkner B (2010). Hypertension in children and adolescents: epidemiology and natural history. Pediatric Nephrology;25:1219-1224.

4) Chiolero A, Bovet P, Paradis G (2013). Screening for elevated blood pressure in children and adolescents: a critical appraisal. JAMA pediatrics; 167:266-273.

5) McCrindle BW (2010). Assessment and management of hypertension in children and adolescents. Nature reviews. Cardiology; 7:155-163.

6) Urbina EM, Khoury PR, McCoy C, Daniels SR, Kimball TR, Dolan LM(2011). Cardiac and vascular consequences of pre-hypertension in youth. The Journal of Clinical Hypertension; 13:332-342.

7) Abolfotouh MA, Sallam SA, Mohammed

AA, Hasab

AA

MS, Loutfy

Prevalence of elevated blood pressure and association with obesity in Egypti an school adolescents.International 
Journal of Hypertension; 2011: 952537. doi: 10.4061/2011/952537.

8) Egypt Demographic and Health Survey (2014). Percentage of adolescents aged 5-19 years who are overweight and obese, by background characteristics. UNICEF. Children in Egypt 2015. A statistical digest. Chapter 5 Child and adult nutrition. Accessed on August 2016 at www.unicef.org/egypt/Ch5.Child_and Adult_Nutrition.pdf.

9) National High Blood Pressure Education Program Working Group on High Blood Pressure in Children and Adolescents. The fourth report on the diagnosis, evaluation, and treatment of high blood pressure in children and adolescents (2004). Pediatrics; 114:555-576.

10) Kelishadi R, Heshmat R, Ardalan G et al. (2014). First report on simplified diagnostic cr iteria for pre-

hypertension and hypertension in a national sample of adolescents from the Middle East and North Africa: the CASPIAN-III study. Jornal de Pediatria; 90: 85-91.

11) Bijlsma MW, Blufpand HN, Kaspers GJ, Bokenkamp A (2014). Why pediatricians fail to diagnose hypertension: a multicenter survey. The Journal of Pediatrics;164:173177.

12) Lu Q, Ma CM, Yin FZ, Liu BW, Lou DH, Liu XL (2011). How to simplify the diagnostic criteria of hypertension in adolescents. Journal of Human Hypertension; 25:159-163.

13) Lauer RM, Clarke WR, Beaglehole R. Level, trend, and variability of blood pressure during childhood: the Muscatine study. Circulation. 1984;69(2):242-9.
14) Hajian-TilakiK

(2014).Sample size estimation in diag nostic test studies of biomedical infor matics. Journal of Biomedical Informatics; 48:193-204.

15) Mourato FA, Lima Filho JL, MattosSda S (2015).

Comparison of different screening met hods for bloodpressure disorders in ch ildren and adolescents. Jornal de Pediatria;91:278-283.

16) World Health Organization (2007). Growth reference, 5-19 years. Heightfor-age (5-19 years). Height-for-age 5-19 years (percentiles)/sex. Accessed on August 2016 at http://www.who.int/growthref/who20 07_height_for_age/en/.

17) Zhu W, Zeng N, Wang N (2010). Sensitivity, Specificity, Accuracy, Associated Confidence Interval and ROC Analysis with Practical SAS Implementations. In Proceedings, North East SAS Users Group. Accessed on October 2016 at www.lexjansen.com/nesug/nesug10/hl /hl07.pdf.

18) Ibrahim MM (2013). Problem of hypertension in Egypt. The Egyptian Heart Journal; 65:233-234.

19) Shapiro DJ, Hersh AL, Cabana MD, Sutherland SM, Patel AI (2012). Hypertension screening during ambulatory pediatric visits in the United States, 2000-2009. Pediatrics; 130:604-610.

20) Hansen ML, Gunn PW, Kaelber DC (2007).Underdiagnosis of hypertension in children and adolescents. JAMA; 298:874-879.

21) Redwine KM, Falkner B. Progression of prehypertension to hype rtension in adolescents. CurrHypertens Rep. 2012 Dec;14(6):619-25. doi: 10.1007/s11906-012-0299-y.

No. 1 January 2018


22) Zhang CX, Shi JD, Huang HY, Feng LM, Ma J (2012). Nutritional status and its relationship with blood pressure among children and adolescents in South China. European Journal of Pediatrics; 171:1073-1079.

23) Bozza R, Campos Wd, Barbosa Filho VC., StabeliniNeto A, Silva MP, Maziero RS (2016). High Blood Pressure in Adolescents of Curitiba: Prevalence and Associated Factors. ArquivosBrasileiros de Cardiologia; 106:411-418.

24) Ladapo TA, Fajolu IB, Adeniyi OF, et al. (2016). Blood pressure to height ratio as a screening tool for prehypertension a nd hypertension in adolescents.

Nigerian Journal of Clinical Practice;19:401-406.

25) Marras AR, Bassaroe PP, Ruscazio M (2009). The prevalence of paediatric hypertension, emphasising the need to use specific population references: the Sardinian Hypertensive Addolecents Research Program Study. Cardiology in the Young;19:2333-2338.

26) Brady TM, Fivush B, Parekh RS, Parekh RS, Flynm JT (2010). Racial differences among children with primary hypertension. Pediatrics;126:931-937.

27) Ejike CE (2011). Blood pressure to height ratios as simple, sensitive and specific diagnostic tools for adolescent (pre)hypertension in Nigeria. Italian Journal of Pediatrics; 37:30. doi: 10.1186/1824-7288-37-30.

28) Dong B, Wang Z, Wang HJ, Ma J (2015).
Blood pressure-to- height ratio for screening prehypertensi on and hypertension in Chinese childre n. Journal of Human Hypertension; 29:618-622.

29) Lu Q, Ma C, Yin F, Wang R, Lou D, Liu $X$ (2013). Blood pressure-toheight ratio as a screening measure for identifying chi ldren with hypertension. European Journal of Pediatrics;172:99-105.

30) Guo $X$, Zheng L, Li Y, Zhang $X, Y u$ S, Sun $Y$ (2013). Blood pressure to height ratio:

A novel method for detecting hyperten sion in paediatric age groups. Paediatrics \& Child Health;18: 65-69.

31) Sinaiko AR (1996). Hypertension in children. The New England journal of medicine;335:1968-1973.

32) Kelishadi R, Bahreynian M, Heshmat R, et al. (2016). Accuracy of Blood Pressure-toHeight Ratio to Define Elevated Blood Pressure in Children and Adolescents: The CASPIAN-IV Study. Pediatric Cardiology;37:378-385.

33) Galescu O, George M, Basetty $S$, et al. (2012). Blood pressure over height ratios: Simple and accurate method of detecting elevated blood pressure in children. International Journal of Pediatrics;2012:253497. doi: 10.1155/2012/253497.

34) Ejike CE, Yin FZ (2013). Blood pressure-to-height ratio simplifies the diagnosis of hypertension in Nigerian children. Journal of Tropical Pediatrics;59:160-161.

35) Deeks JJ, Altman DG (2004). Diagnostic tests 4: likelihood ratios. BMJ;329:168-169. 
Mirella Youssef Tawfik, Accuracy of blood pressure-to-height ratio for screening

Table 1: Clinical characteristics of the studied participants $(\mathrm{N}=1707)$

\begin{tabular}{|c|c|c|c|c|c|c|c|}
\hline Age/gender & Height (cm) & Weight (Kg) & BMI (kg/m2) & SBP (mmHg) & DBP (mmHg) & $\begin{array}{c}\text { SBPHR } \\
(\mathbf{m m H g} / \mathbf{c m})\end{array}$ & $\begin{array}{c}\text { DBPHR } \\
(\mathbf{m m H g} / \mathbf{c m})\end{array}$ \\
\hline & \multicolumn{7}{|c|}{$\mathrm{X} \pm \mathrm{SD}$} \\
\hline \multicolumn{8}{|l|}{11 yearsn(\%) } \\
\hline Bovs (175) & $143.2 \pm 5.9$ & $49.9 \pm 13.2$ & $24.5 \pm 7$ & $99.4 \pm 9.6$ & $60.9 \pm 8.1$ & $.68 \pm .074$ & $.41 \pm .56$ \\
\hline Girls (173) & $144 \pm 6.3$ & $48.2 \pm 10.8$ & $23.4 \pm 5.6$ & $98.1 \pm 9.1$ & $58.9 \pm 7.6$ & $.68 \pm .073$ & $.41 \pm .59$ \\
\hline$p$ value & .200 & .203 & .105 & .231 & $.016^{*}$ & .895 & .977 \\
\hline \multicolumn{8}{|l|}{12 yearsn(\%) } \\
\hline Bovs (169) & $150.7 \pm 6.1$ & $51.8 \pm 13.4$ & $22.7 \pm 5.4$ & $99.7 \pm 10.3$ & $61.1 \pm 8$ & $.66 \pm .073$ & $.39 \pm .055$ \\
\hline Girls (171) & $151.5 \pm 6.4$ & $52.3 \pm 12.3$ & $22.8 \pm 5.4$ & $98.7 \pm 9.6$ & $59.8 \pm 8.1$ & $.65 \pm .067$ & $.39 \pm .054$ \\
\hline$p$ value & .289 & .712 & .841 & .337 & .151 & .185 & .758 \\
\hline \multicolumn{8}{|l|}{13 yearsn(\%) } \\
\hline Boys (167) & $155.4 \pm 7.8$ & $50.1 \pm 13.1$ & $20.7 \pm 4.8$ & $101.6 \pm 11.6$ & $62.9 \pm 8.9$ & $.63 \pm .076$ & $.38 \pm .057$ \\
\hline Girls (165) & $155.5 \pm 7.9$ & $51.3 \pm 12.6$ & $21.4 \pm 5.7$ & $99.5 \pm 11.6$ & $60.5 \pm 9.1$ & $.64 \pm .077$ & $.39 \pm .062$ \\
\hline$p$ value & .975 & .414 & .234 & .104 & $.016^{*}$ & .819 & .219 \\
\hline \multicolumn{8}{|l|}{14 yearsn(\%) } \\
\hline Boys (170) & $165 \pm 9.7$ & $55.7 \pm 15.2$ & $20.1 \pm 3.7$ & $105 \pm 14.1$ & $65.8 \pm 10.1$ & $.64 \pm .088$ & $.40 \pm .061$ \\
\hline Girls (172) & $159.5 \pm 6.8$ & $56.2 \pm 10.9$ & $22.1 \pm 4$ & $103.6 \pm 12.5$ & $70.9 \pm 7.2$ & $.65 \pm .077$ & $.44 \pm .047$ \\
\hline$p$ value & $.000 * * *$ & .704 & $.000^{* * *}$ & .328 & $.000^{* * *}$ & .070 & $.000^{* * *}$ \\
\hline \multicolumn{8}{|l|}{15 yearsn(\%) } \\
\hline Boys (172) & $169.4 \pm 7.2$ & $63.6 \pm 11.4$ & $21.7 \pm 2.9$ & $105.3 \pm 12.8$ & $65.1 \pm 8.8$ & $.62 \pm .072$ & $.38 \pm .050$ \\
\hline Girls (173) & $163.4 \pm 6.7$ & $63.5 \pm 11.3$ & $23.9 \pm 4.9$ & $104.2 \pm 12$ & $66.1 \pm 9.1$ & $.64 \pm .078$ & $.40 \pm .058$ \\
\hline$p$ value & $.000^{* * * *}$ & .987 & $.000 * * *$ & .428 & .339 & $.024 *$ & $.001 * *$ \\
\hline
\end{tabular}

*Statistically significant at $p<0.05 ; * *$ statistically significant at $p<0.01 ; * * *$ statistically significant at $p$ $<0.001$ 
Table 2: Pattern of blood pressure in the studied participants

\begin{tabular}{|c|c|c|c|c|}
\hline BP & $\begin{array}{c}\text { Boys (853) } \\
\text { n (\%) }\end{array}$ & $\begin{array}{c}\text { Girls (854) } \\
\text { n (\%) }\end{array}$ & Total (1707) & $p$ value \\
\hline \multicolumn{5}{|l|}{ SBP } \\
\hline Normal & $762(89.3)$ & $764(89.5)$ & $1526(89.4)$ & \multirow{4}{*}{0.757} \\
\hline Pre-hypertension & $53(6.2)$ & $59(6.9)$ & $112(6.5)$ & \\
\hline Hypertension stage I & $25(3)$ & $19(2.2)$ & $44(2.6)$ & \\
\hline $\begin{array}{l}\text { Hypertension stage } \\
\text { II }\end{array}$ & $13(1.5)$ & $12(1.4)$ & $25(1.5)$ & \\
\hline \multicolumn{5}{|l|}{ DBP } \\
\hline Normal & $782(91.7)$ & $788(92.3)$ & $1570(92)$ & \multirow{4}{*}{$0.320 *$} \\
\hline Pre-hypertension & $50(5.8)$ & $55(6.4)$ & $105(6.2)$ & \\
\hline Hypertension stage I & $12(1.4)$ & $7(.8)$ & $19(1.1)$ & \\
\hline $\begin{array}{l}\text { Hypertension stage } \\
\text { II }\end{array}$ & $9(1.1)$ & $4(.5)$ & $13(.7)$ & \\
\hline
\end{tabular}

* $p$ value calculated using fisher's exact test 
Mirella Youssef Tawfik, Accuracy of blood pressure-to-height ratio for screening

25

Table 3: Correlations of BP and BPHR with clinical characteristics of the studied participants

\begin{tabular}{|c|c|c|c|c|c|c|}
\hline & Age & Height & Weight & BMI & SBP & DBP \\
\hline SBPHR & .207 & -.363 & .021 & .255 & .806 & .441 \\
\hline$p$ value & .050 & $.000 *$ & .382 & $.000 *$ & $.000 *$ & $.000 *$ \\
\hline DBPHR & .003 & -.194 & .049 & .177 & .532 & .821 \\
\hline$p$ value & .914 & $.000 *$ & .055 & $.000 *$ & $.000 *$ & $.000 *$ \\
\hline SBP & .208 & .214 & .266 & .144 & & .606 \\
\hline$p$ value & $.000 *$ & $.000 *$ & $.000 *$ & $.000 *$ & & $.000 *$ \\
\hline DBP & .296 & .241 & .209 & .065 & .606 & \\
\hline$p$ value & $.000 *$ & $.000 *$ & $.000 *$ & $.000 *$ & $.000 *$ & \\
\hline
\end{tabular}

$*$ Statistically significant at $<0.001$ 
Table 4: Optimal cutoff points of SBPHR and DBPHR for identifying elevated blood pressure and corresponding sensitivity, specificity, predictive values, and likelihood ratios

\begin{tabular}{|c|c|c|c|c|c|c|c|c|c|c|c|c|c|c|}
\hline \multirow{2}{*}{$\begin{array}{c}\text { SBPH } \\
\mathbf{R}\end{array}$} & \multicolumn{7}{|c|}{ Pre-hypertension } & \multicolumn{7}{|c|}{ Hypertension } \\
\hline & $\begin{array}{c}\text { Cutof } \\
\text { f } \\
\text { point }\end{array}$ & $\begin{array}{c}\text { Sensitivi } \\
\text { ty }\end{array}$ & $\begin{array}{c}\text { Specifici } \\
\text { ty }\end{array}$ & $\begin{array}{c}+\mathbf{P} \\
\mathbf{V}\end{array}$ & $-\mathbf{P V}$ & $\begin{array}{l}\text { LR } \\
+\end{array}$ & LR- & $\begin{array}{c}\text { Cutof } \\
\mathbf{f} \\
\text { point }\end{array}$ & $\begin{array}{l}\text { Sensitiv } \\
\text { ity }\end{array}$ & $\begin{array}{l}\text { Specifi } \\
\text { city }\end{array}$ & $\begin{array}{l}\mathbf{+ P} \\
\mathrm{V}\end{array}$ & $-P V$ & LR+ & LR- \\
\hline Boys & .69 & .88 & .77 & .20 & .99 & 3.8 & .15 & .75 & 1.0 & .92 & .38 & 1 & $\begin{array}{c}12 . \\
5\end{array}$ & 0 \\
\hline Girls & .71 & .93 & .87 & .32 & .99 & 7.1 & .08 & .75 & .94 & .92 & .28 & 1 & $\begin{array}{c}11 . \\
7 \\
\end{array}$ & $\begin{array}{c}0.0 \\
6 \\
\end{array}$ \\
\hline \multirow[b]{2}{*}{$\begin{array}{l}\text { DBPH } \\
\mathbf{R}\end{array}$} & \multicolumn{7}{|c|}{ Pre-hypertension } & \multicolumn{7}{|c|}{ Hypertension } \\
\hline & $\begin{array}{c}\text { Cutof } \\
f \\
\text { point }\end{array}$ & $\begin{array}{l}\text { Sensitiv } \\
\text { ity }\end{array}$ & $\begin{array}{l}\text { Specific } \\
\text { ity }\end{array}$ & $\begin{array}{l}+\mathbf{P} \\
\mathrm{V}\end{array}$ & $\overline{P V}$ & $\begin{array}{c}\text { LR } \\
+\end{array}$ & LR- & $\begin{array}{c}\text { Cutof } \\
\mathbf{f} \\
\text { point }\end{array}$ & $\begin{array}{l}\text { Sensiti } \\
\text { vity }\end{array}$ & $\begin{array}{l}\text { Specifi } \\
\text { city }\end{array}$ & $\begin{array}{l}+\mathbf{P} \\
\mathrm{V}\end{array}$ & $-P V$ & LR+ & LR- \\
\hline Boys & .44 & .97 & .85 & .28 & .99 & 6.5 & .03 & .49 & 1.0 & .93 & .27 & 1 & $\begin{array}{c}14 . \\
3\end{array}$ & 0 \\
\hline Girls & .46 & .95 & .86 & .25 & .99 & 6.8 & .36 & .50 & 1.0 & .95 & .15 & 1 & 20 & 0 \\
\hline
\end{tabular}


Figure 1: Area under the ROC curves of SBPHR and DBPHR for diagnosing elevated blood pressure by gender

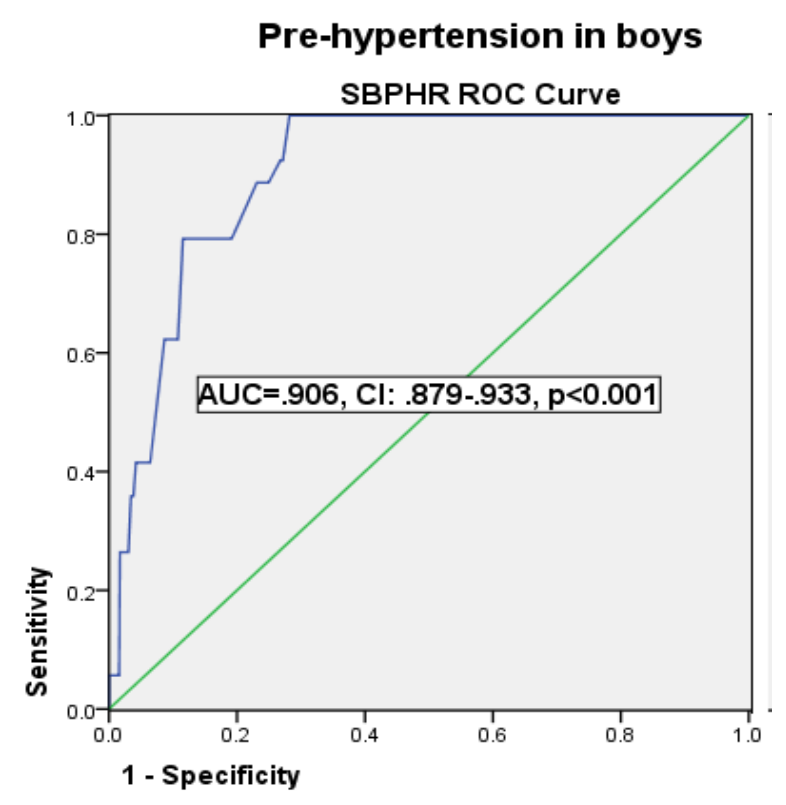

Diagonal segments are produced by ties

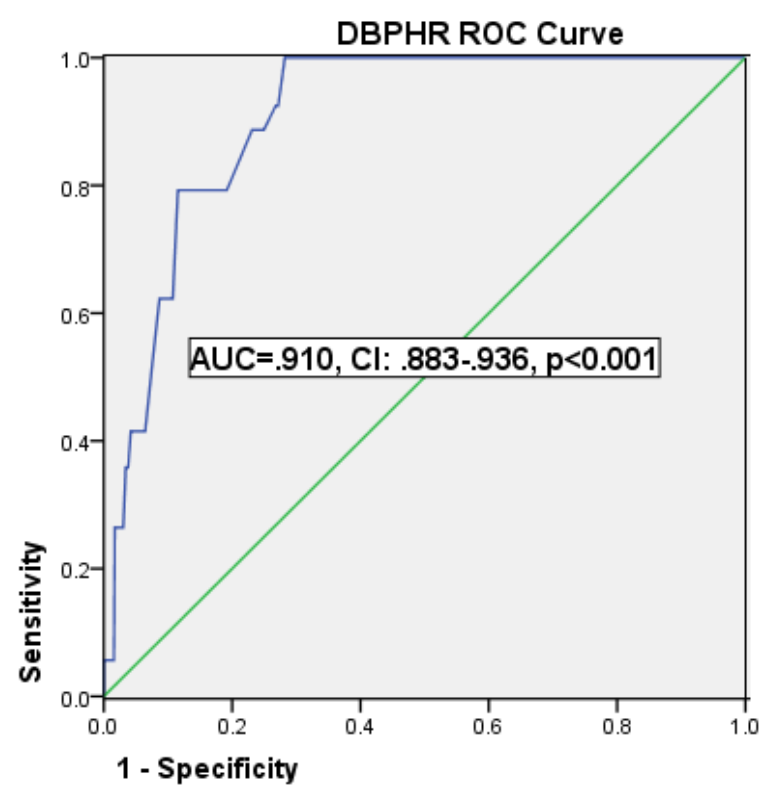

Diagonal segments are produced by ties.
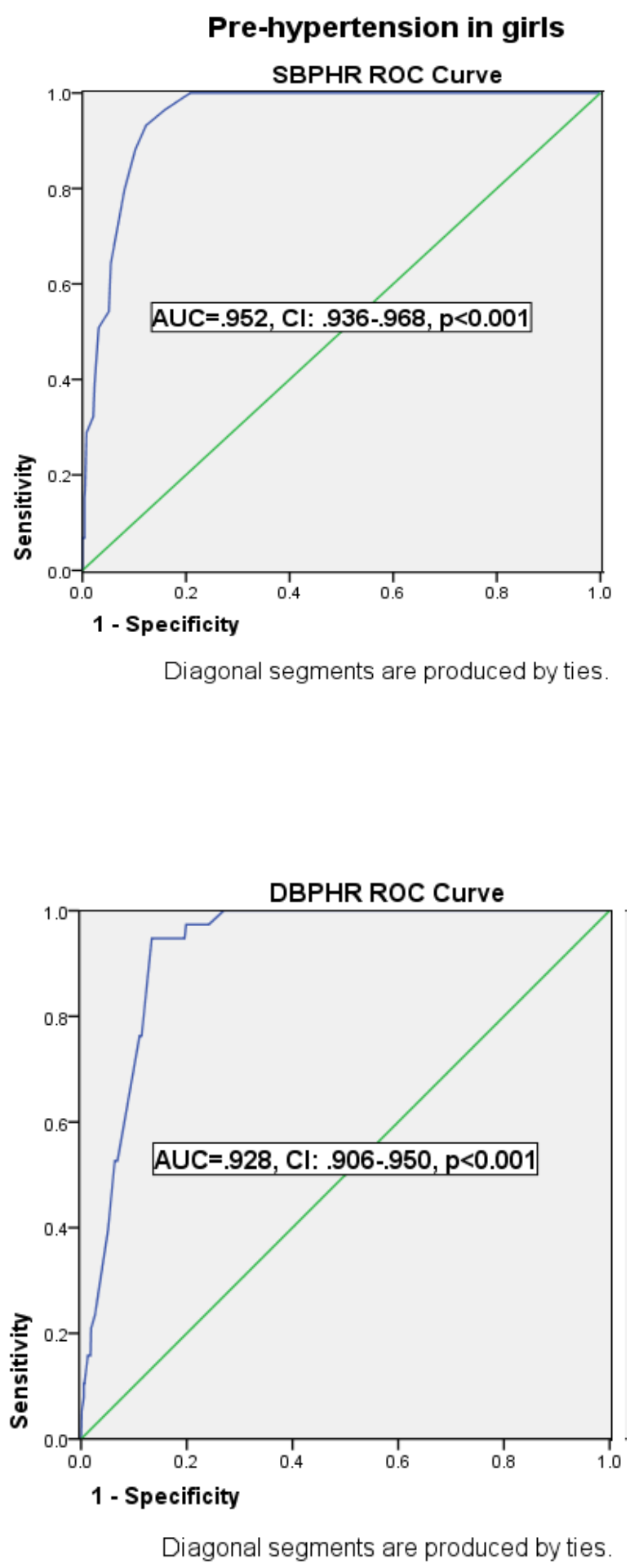
Hypertension in boys

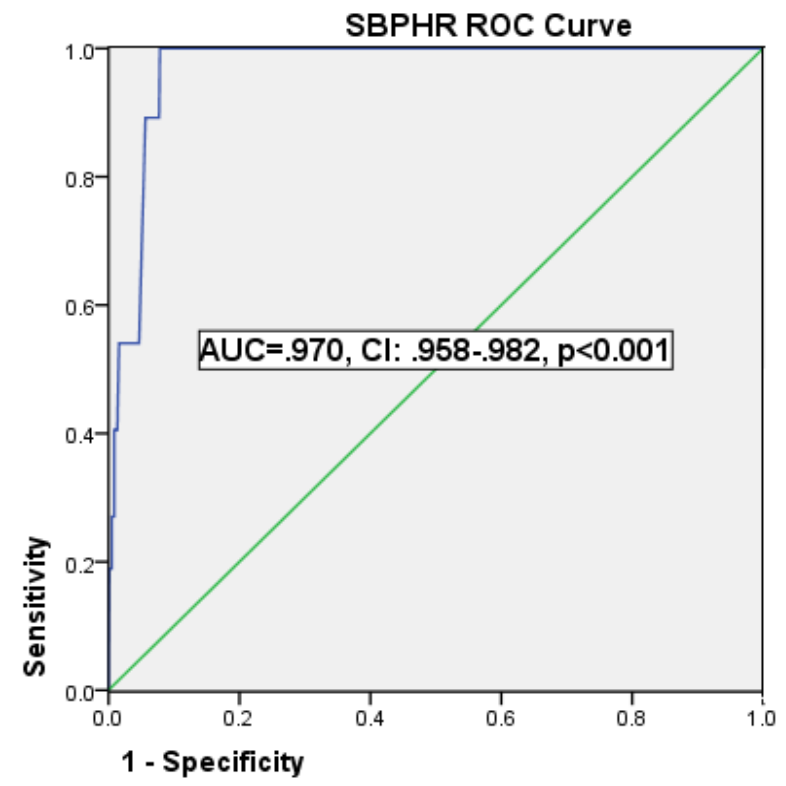

Diagonal segments are produced by ties.

Hypertension in girls

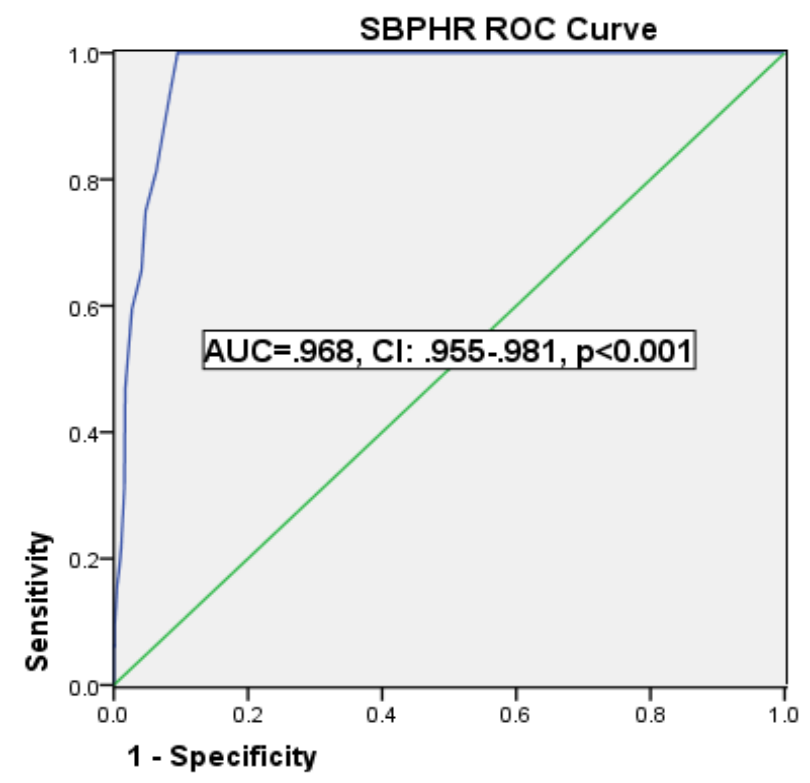

Diagonal segments are produced by ties. 


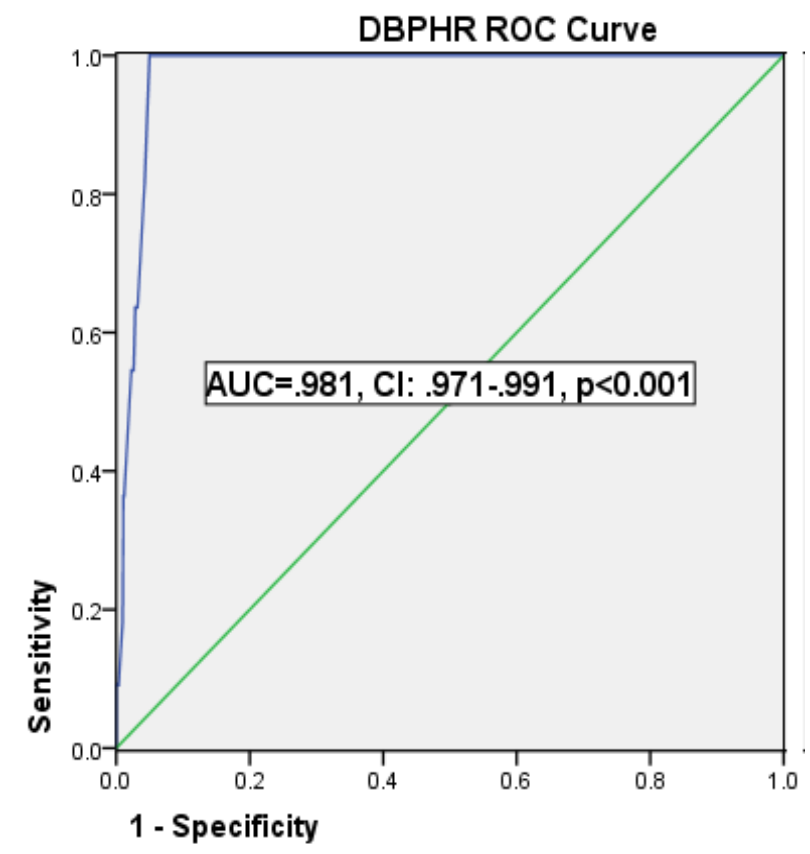

Diagonal segments are produced by ties.

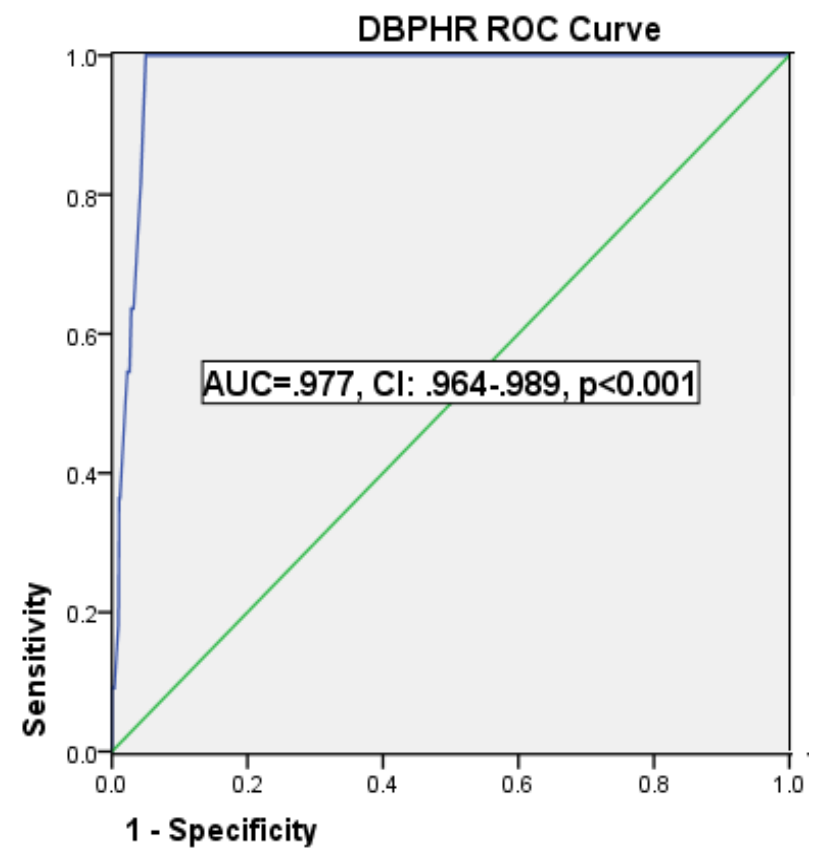

Diagonal segments are produced by ties. 